\title{
OBLIGACIÓN DE INFORMACIÓN Y ASIMETRÍAS DE INFORMACIÓN EN EL MERCADO BANCARIO COLOMBIANO*
}

\author{
Juliana Devis Cantilloa \\ María del Pilar Gómez Quiñones ${ }^{\mathrm{b}}$ \\ Erika López Pontón
}

* DOI: https://doi.org/10.18601/01245996.v21n41.07. Recepción: 13-072017, modificación final: 01-04-2019, aceptación: 14-05-2019. Sugerencia de citación: Devis C., J., Gómez Q., M. y López P., E. (2019). Obligación de información y asimetrías de información en el mercado bancario colombiano. Revista de Economía Institucional, 21(41), 161-186.

a Maestría en Política Económica Internacional. Instituto de Estudios Políticos, París, Francia, [juliana.deviscantillo@sciencespo.fr], [https://orcid. org/0000-0001-5840-6941].

b Maestría en Asuntos Públicos. Instituto de Estudios Políticos, París, Francia, [mariadelpilar.gomezquinones@sciencespo.fr], [https://orcid.org/00000001-7694-804X].

c Doctora en Economía. Profesora de economía. Instituto de Estudios Políticos, París, Francia, [erika.lopezponton@sciencespo.fr], [https://orcid. org/0000-0002-0383-4671]. 


\section{Obligación de información y asimetrías de información en el mercado bancario colombiano}

Resumen Las asimetrías de información requieren la intervención del Estado para regular los contratos. En Colombia se creó la ley de Habeas Data para manejar los conflictos derivados de la asimetría de información entre usuarios y entidades financieras. No obstante, la capacidad de este instrumento jurídico para resolver esta imperfección es limitada, como muestran los resultados de este artículo, basados en una revisión exhaustiva de sentencias de la Corte Constitucional.

Palabras claves: asimetría de información, análisis económico del derecho, obligación de información, sector bancario; JEL: G21, G28

The obligation of information and information asymmetries in the Colombian banking market

Abstract The information asymmetry increases the transaction costs. This fact calls the State's regulation on the contracts developed by the market's agents in order to get efficient results. In Colombia, the Habeas Data law was created to manage conflicts arising from the asymmetry of information between users and financial entities. However, its ability to solve this market's imperfection in the banking sector is still limited. In this article, we present results that validate the previous statement based on the analysis of this legal instrument, retaking concepts of the "Law and Economics" and a comprehensive review of Constitutional Court decisions.

Keywords: Information asymmetry, law and economics, obligation of information, banking sector; JEL: G21, G28

\section{Obrigação de informação e assimetrias de informação no mercado bancário colombiano}

Resumo As assimetrias de informação exigem a intervenção do Estado para regular os contratos. Na Colômbia, a lei do Habeas Data foi criada para lidar com os conflitos decorrentes da assimetria de informação entre usuários e entidades financeiras. No entanto, a capacidade desse instrumento jurídico para resolver essa imperfeição é limitada, como mostram os resultados deste artigo, com base numa revisão exaustiva das decisões do Tribunal Constitucional.

Palavras-chaves: assimetria de informação, análise econômica do direito, obrigação de informação, setor bancário; JEL: G21, G28 
T as imperfecciones del mercado derivadas del comportamiento Loportunista de los agentes, de las asimetrías de información, del riesgo moral y de la selección adversa justifican la intervención pública a través de agencias, normas e instrumentos jurídicos.

Para los economistas, la "obligación de información” es un instrumento jurídico que puede reducir la asimetría de información en los intercambios entre agentes. El objetivo de este artículo es verificar el alcance de esta obligación en la reducción de las asimetrías de información en el sector bancario colombiano. No pretende medir sino explicar de qué manera dicha obligación puede limitar las asimetrías de información entre las entidades financieras y sus usuarios, mediante un análisis cualitativo de 25 sentencias de la Corte Constitucional, emitidas entre 2010 y 2018, relacionadas con esta obligación establecida por la Ley 1328 de 2009. Los resultados no son generalizables pero permiten entender los defectos del mercado e identificar los conflictos entre usuarios y entidades financieras.

La revisión de la literatura sobre el caso colombiano muestra la originalidad de la tesis planteada en el artículo y del método empleado para demostrarla. Por un lado, la mayoría de los estudios adoptan una perspectiva jurídica sobre la obligación de información de las entidades financieras con los usuarios de sus servicios (Blanco, 2012). Por otro lado, los trabajos que establecen el fundamento económico y jurídico de las obligaciones de información (Monsalve y Rodado, 2010; Muñoz, 2012), no analizan empíricamente su eficiencia. En el ámbito internacional cabe citar los trabajos de Cuena (2017) y Alonso y Monge (2017).

La primera sección del artículo sintetiza los aspectos teóricos. Enuncia brevemente las hipótesis sobre el comportamiento de los agentes y subraya sus efectos sobre los intercambios en el mercado. La segunda sección describe el marco normativo e institucional de la obligación de información y la tercera presenta los resultados.

\section{FUNDAMENTOS TEÓRICOS}

El análisis económico del derecho como disciplina se inició en la Universidad de Chicago en los años setenta (Cooter y Ulen, 2016). Esta disciplina aplica instrumentos del análisis económico a fenómenos que, en principio, son puramente jurídicos. Cabe citar, por ejemplo, el trabajo sobre la responsabilidad de Calabresi (1970), el de Becker (1968) sobre el derecho penal, y el de Daughety y Reinganum (2005) sobre negociaciones y mediaciones jurídicas. 
La economía y el derecho tienen al menos tres conceptos en común: la incompletitud de los contratos, el riesgo moral y las asimetrías de información. El análisis económico y en particular la economía heterodoxa han avanzado notablemente en la comprensión y formalización de estos conceptos, de modo que los resultados hoy pueden ser utilizados por quienes aplican la ley; sin que la eficiencia económica se sobreponga a las normas, puesto que el objetivo de estas últimas es ante todo la regulación social.

En el análisis económico del derecho el contrato es un instrumento clave de la economía legal. En un contrato, cada parte se compromete a limitar su libertad futura para reducir la incertidumbre de los intercambios de mercado. Sin embargo, el contrato se establece en un contexto económico desigual. El poder de negociación está mal distribuido en la sociedad. La hipótesis de asimetrías de información ayuda a entender esta desigualdad. La asimetría de información alude a la calidad de la información, como sucede en casos de fraude o de transmisión de información falsa, errada o incompleta. Si una de las partes está mal informada al momento de firmar el contrato, luego surgirán problemas que pueden provocar conflictos, llevar a la modificación del contrato o requerir la intervención de un juez.

Los economistas analizan este tipo de situación por medio de la relación principal/agente. El principal propone el contrato y el agente puede aceptar o rechazar su oferta. Pero el agente puede disponer de ventajas de información, por ejemplo, un mejor conocimiento de sus propias capacidades. Este es el problema de selección adversa, estrechamente relacionado con la hipótesis de que los agentes tienen una racionalidad limitada (Ahlin y Waters, 2016). Esta ventaja de información también se puede presentar en la ejecución del contrato, porque el agente puede adoptar un comportamiento oportunista sin irrespetar los términos del contrato. Este es el problema de riesgo moral, relacionado con la hipótesis del comportamiento oportunista de los agentes (Coase, 1960).

En su famoso artículo sobre el "mercado de los limones" (1970), Akerlof demostró que la selección adversa podía perjudicar los intercambios de mercado, y desestabilizar una actividad rentable. Akerlof llamó así al mercado de automóviles usados, en el que solo los vendedores conocen la calidad del auto que venden. Inicialmente, los autos de buena calidad tienen un precio mayor que los que están en mal estado. Pero los vendedores de automóviles de mala calidad rápidamente alinean, en forma oportunista, su precio de venta al de los autos de buena calidad. Así, los compradores no pueden distinguir, 
por el precio, los automóviles de buena y mala calidad. Frente a la posibilidad de adquirir un auto de mala calidad a un precio elevado, los compradores negocian los precios hacia abajo y llevan a que los vendedores de autos de buena calidad se retiren. En el mercado solo quedan, entonces, automóviles de mala calidad.

Este ejemplo muestra que algunas transacciones no se llevan a cabo debido a la incertidumbre del mercado, lo que provoca una mala asignación de los recursos. En cuanto al riesgo moral, la posible solución no es tan solo contractual. A través de la competencia y de la reputación, el mercado resuelve parte del problema. Pero esta solución también es imperfecta porque los incentivos para reducir el riesgo moral son costosos. Se han propuesto varios mecanismos adicionales para enfrentar estos problemas. Por ejemplo, la adopción de la obligación de información para reducir las asimetrías ab initio de la transacción, la cual se analiza más adelante.

Uno de los objetivos del análisis económico del derecho es garantizar la celebración de contratos cuya ejecución es deseable desde el punto de vista del bienestar social. Sin embargo, las externalidades y los costos de transacción dificultan la asignación de los recursos y alejan del bienestar social. Las externalidades generan costos de transacción, pues los agentes deben negociar hasta llegar a un acuerdo sobre los términos del contrato o la asignación de los recursos. Las externalidades positivas o negativas afectan a las partes implicadas en la transacción y a terceros.

$\mathrm{E} 1$ derecho de los contratos ofrece el marco legal necesario para manejar externalidades. Por ejemplo, reglas de compensación en caso de abuso por una de las partes o un tercero. Sin embargo, la racionalidad limitada, el comportamiento oportunista y la asimetría de información generan costos y hacen que los contratos sean incompletos e imperfectos (Macneil, 1980; Williamson, 1979).

Por último, los defectos del mercado y las fallas de los contratos justifican la intervención pública (Stiglitz, 1992). El ejemplo típico es la adopción de impuestos o normas para compensar o evitar los perjuicios de la contaminación causada por cierta industria. En Derecho, un juez puede intervenir cuando no se respeta una ley y la situación se estima injusta, por ejemplo, a causa de una acción de mala fe de una de las partes del contrato. La igualdad social es un elemento clave en la intervención de las autoridades jurídicas. La Corte Constitucional de Colombia resalta que

el juez, en el Estado social de derecho también es un portador de la visión institucional del interés general. El juez, al poner en relación la 
Constitución -sus principios y sus normas- con la ley y con los hechos hace uso de una discrecionalidad interpretativa que necesariamente delimita el sentido político de los textos constitucionales. En este sentido la legislación y la decisión judicial son ambas procesos de creación de derecho (Sentencia T-406/92).

Sin embargo, la intervención de un juez también es imperfecta por razones que van desde la incorrecta definición de las normas, pasando por los conflictos de interés y la subjetividad de las apreciaciones, hasta la deficiencia institucional (Medema, 1997).

\section{MARCO JURÍDICO DE LA OBLIGACIÓN DE INFORMACIÓN EN LA BANCA}

La obligación de información podría corregir las fallas de mercado antes descritas. En primer lugar, puede reducir los costos de transacción ex ante y ex post, al obligar a las partes de un contrato a revelar cierta o toda la información relacionada con el intercambio. En segundo lugar, puede disminuir la incertidumbre acerca del comportamiento oportunista y los problemas de riesgo moral, selección adversa, asimetría de información, contratos incompletos, contratos imperfectos. En el "mercado de los limones" de Akerlof, la obligación de información habría evitado que los vendedores de autos de buena calidad salieran del mercado, pues todos los vendedores habrían tenido que revelar la verdadera calidad de sus automóviles y los compradores habrían recibido la información necesaria para comparar los autos en venta.

Antes de verificar el alcance de la obligación de información en la corrección de la asimetría de información, debemos entender en qué consiste este instrumento jurídico. Para empezar, recordemos la complejidad de la información requerida en las operaciones financieras, en especial en aquellas relacionadas con préstamos bancarios. Los derechos y obligaciones del consumidor financiero establecen que la información suministrada por la entidad financiera sea cierta, suficiente, oportuna y verificable, y que les permita conocer adecuadamente sus derechos, obligaciones y los costos en sus relaciones con las entidades vigiladas ${ }^{1}$. Además, los consumidores financieros deben tener a su disposición las características de los productos o servicios suministrados. En particular, la información debe permitir y facilitar la comprensión y la comparación con los demás productos y servicios ofrecidos en el mercado. Además, deben recibir información sobre

${ }^{1}$ El consumidor financiero es todo cliente, usuario o cliente potencial de los productos o servicios of recidos por las entidades sometidas a la inspección y vigilancia de la Superintendencia Financiera (Ley 1328 de 2009, art.2). 
los mercados y las actividades de las entidades financieras, y sobre los mecanismos de protección establecidos para defender sus derechos.

Por su parte, la información que debe proporcionar el consumidor financiero debe permitir que la entidad vigilada determine su situación financiera y profesional, así como su capacidad de pago mediante un análisis detallado de los egresos mensuales (servicios públicos, alimentación, educación, personas a su cargo, arriendo, impuestos, salud, obligaciones financieras, entre otros gastos). Esta información se obtiene de documentos suministrados por el consumidor financiero, por ejemplo, un certificado laboral (que indica el cargo, el sueldo, la antigüedad y el tipo de contrato), un certificado de ingresos y retenciones, comprobantes de pago de nómina, extractos bancarios y declaraciones de renta.

La obligación de información financiera fue reglamentada en Colombia por la Ley 1328 de 2009, inicialmente un complemento de la Ley 1266 de 2008, conocida como Ley de Habeas Data. Esta última solo hacía énfasis en la protección de datos de carácter financiero y comercial. Advirtiendo la importancia de la información altamente calificada y de un componente pedagógico como base del equilibrio de las relaciones entre consumidores financieros y entidades vigiladas, la Ley 1328 de 2009 buscaba promover un crecimiento estable y confiable de la economía nacional. Sus artículos 9 y 10 describen el contenido mínimo de la información y su oportunidad, es decir, sus características, los derechos y obligaciones de los interesados y las consecuencias de un irrespeto potencial del contrato. Según la Ley, la obligación de información busca equilibrar las relaciones entre entidades financieras y consumidores para alcanzar el crecimiento económico a pesar de las asimetrías de información. Por ello, en Colombia la obligación de información es un instrumento menos hostil y más incluyente, no solo por la simplificación de la información de uso masivo, sino también por la reglamentación de todos los aspectos relativos al derecho de información. Así, es una norma dirigida al consumidor financiero más que a las entidades vigiladas ${ }^{2}$.

En esta Ley se destaca el artículo 8 que establece un Sistema de Atención al Consumidor Financiero (SAC), uno de los principales mecanismos de protección a los particulares ${ }^{3}$. Además, el artículo 3

${ }^{2}$ El artículo 1 especifica que su objetivo es establecer los principios que rigen la protección de los consumidores financieros en las relaciones entre estos y las entidades vigiladas.

${ }^{3}$ Esta Ley consagra la educación financiera como un principio de protección (art. 3, literal f), un derecho del consumidor financiero (art. 5, literal d), una práctica de protección (art. 6), una obligación especial de las enti- 
prevé una adecuada educación financiera de los consumidores acerca de las normas de los mercados, las operaciones bancarias y los servicios disponibles que haga énfasis en los riesgos de utilizar estos servicios. Con el SAC, las entidades financieras están obligadas a informar a sus usuarios sobre sus productos, servicios y tarifas, así como sobre los procedimientos para quejas y reclamos.

Además, crea la figura del Defensor del Consumidor Financiero, cuyo papel es proteger a los consumidores financieros y actuar como conciliador entre las dos partes, en forma gratuita e independiente. Los consumidores deben estar informados sobre su existencia, sus responsabilidades y la manera de contactarlo.

Otro cambio institucional para proteger al consumidor financiero es la Ley 1480 de 2011 que da facultades jurisdiccionales a la Superintendencia Financiera de Colombia para vigilar la ejecución y el cumplimiento de las obligaciones contractuales de las entidades financieras bajo su inspección. Hoy, la Superintendencia tiene la facultad de dictar fallos en derecho de manera autónoma e imponer sanciones que pueden llegar a 150 salarios mínimos legales mensuales vigentes.

El marco legal de la obligación de información financiera en Colombia también toma en cuenta los intereses de las entidades financieras con otras disposiciones, como las centrales de riesgo y el Habeas Data. Al manejar ahorros del público, las entidades financieras que otorgan créditos ejercen una actividad de interés general: el manejo prudente de los recursos a su disposición justifica la necesidad de obtener información que permita prever qué suerte correrán tales recursos.

Como ya se dijo, la ley 1266 de 2008 se relaciona con el concepto de Habeas Data, un derecho constitucional en Colombia (CPC, art. 15). Este escrito se concentra en el Habeas Data financiero, el derecho de todo individuo a conocer, actualizar y rectificar su información comercial, crediticia y financiera, contenida en centrales de información pública o privada, conocidas como centrales de riesgo.

Las centrales de riesgo almacenan y administran información sobre el comportamiento del pago de obligaciones de las personas naturales y jurídicas ${ }^{4}$. Son entidades de carácter privado e independiente que prestan servicios de información. No solo registran las situaciones de incumplimiento, sino la historia crediticia de todas las personas que cumplen sus obligaciones con los sectores financiero, real y de servicios,

dades vigiladas (art. 7, literal t), y como objetivo (art. 23, literal O) e instrumento de la intervención del Estado (art. 24, literal s); ver Díaz (2013).

${ }^{4}$ Cabe mencionar la Cifin, Datacrédito y Procrédito. 
en particular de telecomunicaciones. $\mathrm{El}$ manejo y procesamiento de estas bases de datos son esenciales en los análisis de crédito de las entidades financieras y en la evaluación del riesgo de los negocios financieros y las operaciones de crédito con sus clientes.

Las centrales de riesgo proporcionan información necesaria para otorgar créditos y préstamos bancarios y ejercen así una actividad de interés general, como lo explica el artículo 10 de la Ley 1266 de 2008. La información positiva permanecerá de manera indefinida en las bases de datos. En cambio, la información negativa permanecerá un término máximo, según la mora. Por ejemplo, en obligaciones en las cuales la mora superó 2 años, permanecerá 4 años, contados desde el día en que se canceló el saldo. En obligaciones nunca canceladas, permanecerá 14 años, contados desde el día del vencimiento de la obligación: 10 años a partir del día en que la obligación se hace exigible más 4 años por el tiempo máximo de permanencia cuando la obligación se extingue por pago u otro medio. El deudor no tiene derecho a impedir que se suministre la información, pero en cualquier caso se requiere su autorización previa, para notificarle cómo transmitirá el reporte a las centrales de riesgo y darle la oportunidad de verificar la validez de dicha información.

La gráfica 1 resume la legislación que se ha mencionado y que determina el uso de la obligación de información como instrumento jurídico, así como su impacto en las relaciones que genera un contrato entre consumidores financieros y entidades financieras. Cada parte dispone de herramientas para conocer sus obligaciones y defender sus intereses. En el caso de las entidades financieras se trata de la Ley 1328 de 2009. Para el consumidor financiero, el Habeas Data es un instrumento de protección y una guía acerca de sus obligaciones.

Gráfica 1

Marco normativo de la obligación de información en Colombia

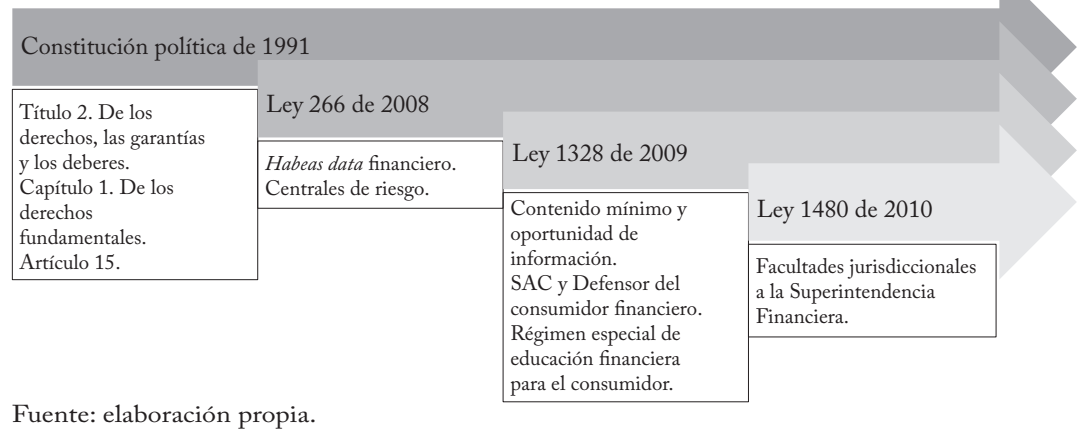

Revista de Economía Institucional, vol. 2i, N. ${ }^{\circ}$ 4I, Segundo semestre/2oig, Pp. i6i-i 86 ISSN OI 24-5996/E-ISSN 2346-2450 
Según la Superintendencia Financiera de Colombia, entre 2008 y 2018 , las quejas aumentaron un $74 \%$, con un total de 1.348 .007 en 2018 , un $35 \%$ de las cuales por problemas de información; entre ellos indebida atención al consumidor financiero (el 49\%, 234.774 quejas), suplantación presunta de persona (el 13\%, 63.618 quejas), inadecuado suministro de información (el 11,5\%, 54.595 quejas) y reporte a centrales de riesgos (el 9\%, 44.793 quejas). Una posible explicación de este aumento puede ser que los consumidores están familiarizados cada vez más con sus derechos (Jiménez, 2014).

Cabe entonces preguntar por qué a pesar de las normas mencionadas hay quejas relacionadas con la obligación de información. Para contestar esta pregunta, analizamos los conflictos entre usuarios y entidades financieras a través de las sentencias de la Corte Constitucional.

\section{RESULTADOS DEL ANÁLISIS}

Recordemos que el análisis cualitativo es a la vez teórico y empírico. La parte empírica proporciona datos y observaciones, la parte teórica proporciona el marco y la definición del tema. $\mathrm{El}$ análisis cualitativo no pretende medir sino explicar los fenómenos mediante descripciones y explicaciones obtenidas a partir de observaciones y muestras reducidas, como entrevistas, contratos, sentencias y otros documentos fiables (Speklé, 2003; Moisanders et al., 2016). Este artículo no mide el impacto de la obligación de información en la asimetría de información; intenta explicar el alcance de dicha obligación en la reducción de las asimetrías de información en el sector bancario colombiano.

El análisis cualitativo se suele equiparar a una simple descripción. No obstante, el creciente número de publicaciones científicas, de manuales metodológicos, de conferencias sobre investigación cualitativa, de software y métodos formales demuestran que esta equiparación es simplista y que las críticas a la validez de los resultados del análisis cualitativo han sido superadas (Prasad, 2016). Este tipo de análisis es muy utilizado en la economía neo-institucional, que enfrenta la dificultad de medir variables como el oportunismo, los costos de transacción, la incertidumbre, el riesgo moral, etc. (Boerner y Macher, 2001; Pinzón, 2010 y 2013).

Ya se señaló que nuestro análisis empírico se basa en el estudio de 25 sentencias de la Corte Constitucional sobre el tema de este artículo. El análisis de la jurisprudencia de la Corte nos permite identificar dos resultados. 


\section{LA OBLIGACIÓN DE INFORMACIÓN NO ELIMINA}

\section{LA ASIMETRÍA DE INFORMACIÓN}

La jurisprudencia que revisamos muestra que, a pesar de las disposiciones asociadas a la obligación de información, los usuarios y las entidades financieras aún esconden o manipulan información para beneficiarse. Mientras que el juez instruye el caso, las dos partes manejan la información en su provecho pues ambas quieren ganar. Incluso después de la sentencia, la asimetría de información sigue caracterizando la relación salvo que esta se rompa una vez anunciada la decisión del juez.

En ninguna de las sentencias revisadas queda resuelto el problema de asimetría de información. Una posible explicación reside es que el juez asume que la información suministrada es completa y veraz, asî como la capacidad de ambas partes para asimilar y usar correctamente la información. Sin embargo, las fallas de mercado y el comportamiento de los agentes mencionados al comienzo del artículo llevan a que las dos partes tomen decisiones erradas: la entidad financiera no posee toda la información y depende de la veracidad de la que dispone. A su vez, es posible que el consumidor financiero no tenga la capacidad suficiente para entender la excesiva y compleja información que está a su alcance, o que no tenga suficiente información. El cuadro 1 presenta una tipología del origen de la asimetría de información presente en las sentencias revisadas.

Cuadro 1

Tipología del origen de la asimetría de información en las sentencias

La asimetría de información se manifiesta La asimetría de información se manifiesta durante la transacción durante el proceso de las sentencias

a. Prescripción de la deuda a. Complejidad de los casos

b. Transgresión de derechos que afectan dere- b. Coordinación de funciones entre entidades chos económicos demandadas

c. Violación de derechos fundamentales que c. Coordinación entre juzgados o falta de afectan derechos económicos claridad en los procesos y en el alcance de las decisiones

d. Información inexistente o dato errado d. Silencio administrativo

e. Hecho superado

Fuente: elaboración propia.

La prescripción de la deuda es uno de los orígenes más frecuentes (sentencias T-1061/10, T-164/10, T-787/10, T-142/10, T-883/13, T-964/10, entre otras). En esencia, el problema proviene de las fechas de prescripción de la deuda y los plazos de los bancos para retirar reportes negativos de las centrales de riesgo. Los demandantes se 
basan en la legislación vigente, que establece un máximo de 10 años para mantener un reporte en las centrales de riesgo. Las entidades demandadas basan su defensa en el cumplimiento del plazo a partir del momento en que la deuda se hace exigible. La Corte resuelve "rápidamente" este problema porque la orden emitida aclara la confusión sobre la legislación vigente. Un ejemplo es la Sentencia T-164 de 2010, que niega el amparo solicitado por el demandante aclarando las condiciones de prescripción de una deuda y los plazos máximos para retirar el reporte negativo. Incluso menciona la ampliación de los plazos de datos negativos como sanción cuando el deudor nunca paga; lo que se puede interpretar como una medida para disuadir a los usuarios del futuro incumplimiento de sus deudas y reducir o eliminar el riesgo moral que sufre la entidad financiera al otorgar un crédito.

Los vacíos causados por la asimetría de información ocasionan una transgresión de los derechos. Es el caso de sentencias donde el demandado fue objeto de sanción penal y la central de riesgo, usando información pública, se extralimita en sus funciones y coarta derechos económicos (T-366/15, T-167/15). En este caso, el problema obedece a la interpretación de la ley y no a que la sanción se extienda de facto a la dimensión económica. Después de una sanción penal se presentan dos situaciones: 1) el demandante cumple la sanción o sigue los procedimientos legales que dictaminó el juez, e intenta reactivar sus relaciones con entidades financieras; 2) el demandante aún está cumpliendo la sanción legal o ya la cumplió y no ha sido validada por una instancia judicial, y busca reactivar sus actividades financieras. En la primera situación, el problema de información se presenta cuando la central de riesgo toma los antecedentes legales del demandante y genera un reporte financiero negativo, el cual no debería existir en la medida en que la dimensión de los derechos es diferente y tiene límites. En la segunda situación el problema de información lo causa el sistema judicial, que no da información clara sobre la situación del demandante, es decir, si cumplió o no las sanciones. Esto suscita otro problema de información porque la central de riesgo hace un reporte negativo sobre el que no se puede tomar ninguna decisión, pues aparentemente la pena sigue en curso y, en ese caso, los derechos económicos del implicado están limitados, por ejemplo, porque su documento de identidad no tiene validez.

Las Sentencias T-167/16, T-246/14, T-142/10 se refieren a la violación de derechos fundamentales que afectan los derechos económicos. El demandante es víctima de un hecho posterior a la transacción con el banco -como la solicitud de un crédito- y esto lo 
lleva a incumplir sus obligaciones. Los procedimientos que siguen las entidades financieras cumplen las cláusulas de cumplimiento establecidas en un contrato financiero estándar, pero hay un problema de información pues no reconocen al demandante como víctima, lo que le exime de cumplir las cláusulas en sentido estricto. El problema surge cuando el banco transmite el reporte negativo a la central de riesgos sin considerar la condición del demandante, quien además cumplió el debido proceso para su reconocimiento legal como víctima. Los jueces ordinarios agravan el problema de información al negar el amparo solicitado por el demandante y, al final, la Corte revisa el caso y toma decisiones de acuerdo con la información recopilada. Aquí, podría existir incluso un problema de riesgo moral, pues la institución financiera conoce la situación del demandante y aun así recurre a las cláusulas contractuales para exigir el pago de su deuda. Además, se generan altos costos para el demandante que, al verse afectado por el reporte negativo que le causa un problema de selección adversa porque ninguna entidad bancaria le presta dinero, debe vender parte de sus activos para pagar deudas y garantizar su sostenimiento. También se generan altos costos de transacción porque las primeras instancias desconocen una condición evidente, y el problema se traslada hasta la Corte.

Una cuarta causa de conflictos es la información inexistente o datos errados (T-803/10, T-811/10,T-658/11, T-036-16, T-419/13, T-129/10, T-136/13, T-672/10). Este problema surge cuando se registra mal un dato o cuando nunca hubo una relación financiera entre el demandante y una entidad financiera. La Sentencia T-658/11 muestra problemas de información a diferentes niveles. 1) la demandante no tiene conocimiento de una transacción con una entidad financiera, en este caso Vestimenta S.A. 2) la demandante después de conocer el reporte negativo del que se enteró al gestionar un crédito de vivienda que le fue negado por su historial financiero, tropieza con un nuevo inconveniente: la información de contacto de Vestimenta S.A. no es verídica y no puede solicitar aclaración, corrección, actualización o rectificación del reporte, lo que la pone en una situación de indefensión. 3) el juez de primera instancia no tiene en cuenta esta circunstancia y toma una decisión basada en información incompleta; además, genera mayores costos administrativos para el sistema judicial porque la demandante inicia nuevos procesos para que se respeten sus derechos. 4) no hay evidencia de que la demandante haya autorizado a Vestimenta S.A. para administrar sus datos crediticios y financieros, lo que vuelve ilegales los datos del reporte negativo. 
Otro caso que se puede incluir en este grupo es el de la Sentencia T-036/16, donde el problema de información existe a tantos niveles que incluso es difícil entender el proceso. El inconveniente comienza cuando el demandante se entera de que tiene antecedentes disciplinarios que no concuerdan con la realidad. Hace los trámites necesarios para recibir aclaración y hacer las correcciones a las que haya lugar, pero no recibe respuesta de la Procuraduría General de la Nación, que está directamente implicada en el caso. Esto lleva a que intervengan tribunales de diferentes ciudades pues los reportes negativos del demandante se registran en diferentes actividades y lugares. Además, puede ser un caso de homonimia que no es posible aclarar por falta de respuesta y claridad de la Procuraduría y de las autoridades judiciales involucradas.

Las sentencias T-017 de 2011 y T-847 de 2010 son ejemplos de casos donde se comunica al demandante una información errónea que provoca el conflicto. La pérdida de documentos y de información y los errores en extractos bancarios, certificados de estado de cuenta, pólizas de seguros provocan muchos de los conflictos de las sentencias analizadas. La obligación de información es completa y precisa con respecto a las obligaciones en materia de comunicación, pero aparecen errores frecuentes en los sistemas informáticos de las entidades financieras. La información así suministrada no es fiable, pero como proviene de documentos expedidos por esas entidades rara vez se la pone en duda, y así da lugar a un conflicto con alto nivel de riesgo moral y oportunismo. En la sentencia T-847/10, la demandante recibió un extracto en el que constaba que su cuenta de ahorros estaba "en ceros por todo concepto" en octubre de 2002. En agosto de 2003 el banco le informó que tenía una deuda en cobro jurídico. Este desacuerdo se aclaró con la presentación del último extracto en su poder y se le informó que era un error del sistema. En marzo de 2004 recibió un telegrama informándole de una deuda pendiente. Este nuevo incidente se solucionó vía fax y teléfono cuando se le dijo de nuevo que era un error del sistema. En mayo de 2009 solicitó un crédito que le fue negado por reportes negativos en las centrales de riesgo debidos a esa supuesta deuda. La Corte involucró a diferentes entidades financieras para verificar la veracidad de la deuda pero no obtuvo pruebas de su existencia: ni solicitudes de crédito, ni estudios de crédito, ni documentos firmados por la demandante. Esta sentencia pone de manifiesto la complejidad de la información que da ventajas que suelen beneficiar a las entidades financieras, la parte menos vulnerable (Vásquez, 2012). La información que estas suministran 
es estándar para todos sus clientes, y cuentan con mayores recursos humanos y financieros para verificarla, como las centrales de riesgo, y por las economías de escala se reducen sus costos de información. Varias sentencias ilustran la complejidad de los conflictos en los que se pone en duda la información suministrada por los bancos.

Las fallas administrativas de las entidades financieras son otra fuente de asimetría de información (sentencias T-198/15, T-136/13). Por ejemplo, la sentencia T-136 de 2013 relaciona el derecho al acceso completo, veraz y oportuno a la información con el derecho de mínimo vital y de vivienda digna (CPC, arts. 13, 16 y 95). En este caso, el demandante, que padece de Alzhéimer, denuncia a su compañía de seguros, que se niega a reconocer el cubrimiento de la póliza por un crédito hipotecario y a pagar el saldo insoluto de su deuda con el banco. La compañía argumenta que el demandante superaba la edad máxima de cobertura al momento de estructurarse la invalidez; según ella, la edad máxima de ingreso para coberturas de incapacidad total y permanente, enfermedad grave y beneficio por hospitalización es de 69 años. El demandante tenía 74 años cuando se reconoció su invalidez. El demandante explica que, con una mesada pensional de un salario mínimo legal vigente y padeciendo Alzhéimer, no puede seguir pagando el crédito bancario y por ello está en mora. Fundamenta su solicitud con el "certificado individual de seguro", un documento que remite la aseguradora al momento de tomar el crédito, donde la casilla de edad máxima de cobertura está vacía.

E1 conflicto obedece a un problema de información porque la compañía de seguros no tiene copia de la póliza, del documento contractual, aunque es una obligación estipulada por el Código de Comercio y reglamentada por la Superintendencia Financiera. Antes de entablar la acción de tutela, el demandante, ejerciendo su derecho, solicitó una copia de la póliza a la compañía de seguros y nunca se le entregó. En este caso, el "certificado individual de seguro" hace oficio de contrato, incompleto. Es entonces un problema de riesgo moral en el que el demandante y la aseguradora afirman decir la verdad sobre sus obligaciones y derechos. Ante la incapacidad de la aseguradora para demostrar que la cobertura está sujeta a una edad máxima y aclarar que la póliza está extraviada, la Corte le ordenó pagar al banco el saldo insoluto de la obligación hipotecaria. Desde el punto de vista económico y jurídico, la obligación de información fue clave para la rápida resolución del conflicto. La Corte pidió en vano a la aseguradora que entregara una copia de la póliza para verificar el límite máximo de edad; en cambio, el certificado de seguro que 
presentó el demandante mostraba la inexistencia de dicho límite. Al no respetar la obligación de comunicación y conservación de la póliza, la aseguradora quebrantó la obligación de información.

El hecho superado también ilustra las asimetrías de información, y muestra de manera clara que los costos de transacción por problemas de información se pueden minimizar e incluso eliminar. La Sentencia T-787/10 trata un caso que también se puede asociar a la "prescripción de la deuda" pero que se resuelve rápidamente porque las centrales de riesgo retiran el reporte negativo durante el proceso judicial y eliminan así el motivo de la tutela, lo que facilita la decisión de confirmar el fallo del juez de primera instancia.

Es posible hacer una tipología de los orígenes de la asimetría de información considerando las dificultades del proceso y los resultados de las sentencias. Empecemos por la complejidad de los casos (T-328A/12), es decir, por el seguimiento de los hechos, pues una de las partes parece tener más información que la otra y no la quiere compartir, o intenta ajustarla a su favor. Muchas veces, el problema de información se debe a la complejidad del caso, como se observa al revisar cada sentencia y seguir los hechos en detalle, por ejemplo, cuándo se hizo la transacción, en qué fecha se incumplió la obligación, cuándo se hizo el reporte y cuánto tiempo debía mantenerse.

Otro aspecto de la complejidad es el carácter único de cada caso. Los servicios, productos y sistemas financieros no son flexibles o adaptables a las necesidades de ciertos consumidores. De modo que se procede caso por caso, sin beneficiarse de las economías de escala. Las leyes cobijan a numerosas personas, pero las situaciones son particulares y cada caso requiere atención específica. Por ejemplo, la Sentencia T-167 de 2016 se refiere a un caso de asimetría de información debida a una comprensión insuficiente del demandante, un desplazado, del procedimiento legal para obtener una vivienda que vulneró sus derechos fundamentales de información y vivienda digna, el cual demandó al Fondo Nacional de Vivienda, al Instituto Social de Vivienda y Hábitat de Medellín, al Ministerio de Vivienda y al Departamento para la Prosperidad Social. E1 demandante -una persona a la que la Constitución da una protección especial por ser adulto mayor, víctima de violencia sexual y desplazamiento forzado, con graves condiciones de salud-pedía su inclusión prioritaria en las bases de datos oficiales para beneficiarios del subsidio de vivienda, atendiendo a criterios de enfoque diferencial, y que se le otorgara el subsidio en Medellín. Interpuso una tutela por considerar vulnerados sus derechos fundamentales de petición, información y vivienda digna 
debido a que esas entidades no dieron una respuesta clara, congruente y de fondo a la solicitud del subsidio para población desplazada y a la falla para proporcionarle una vivienda digna. El fallo del juez consideró que "la acción de tutela es el mecanismo de defensa idóneo para garantizar los derechos fundamentales de las personas que se encuentren en un particular estado de vulnerabilidad o indefensión; en virtud de lo cual requieren de una defensa constitucional preferente" y que se había vulnerado su derecho al Habeas Data al no incorporar en las bases de datos una información completa y veraz sobre la situación de vulnerabilidad, lo que le habría dado ventajas jurídicas.

La falta de coordinación entre entidades demandadas también es una fuente de asimetrías de información (T-672/10, T-847/10, T-787/10). En la mayoría de los casos existen al menos dos instituciones demandadas, la primera suele ser el banco con el que se hizo la transacción que dio origen al problema, y la segunda la central de riesgo que tiene el reporte y entra en juego cuando se definen las responsabilidades y el alcance de las funciones. Esto indica la falta de organización de la información dentro de las entidades y la falta de claridad, entendimiento, apropiación o limitación de las funciones. Además, bien sea en forma intencionada o no, las entidades financieras no articulan su labor con la de otras instituciones involucradas.

Así mismo, la escasa coordinación entre juzgados y la falta de claridad en los procesos y en el alcance de las decisiones generan asimetrías de información, de modo que los jueces de primera instancia niegan los amparos y agravan el problema de información. La falta de coherencia entre las decisiones de las instancias judiciales es ocasionada por diferentes factores: interpretación de la ley (de su vigencia y su alcance); objeto principal del análisis (p. ej., cuando un juez da prioridad al cumplimiento procesal por encima del respeto a los derechos fundamentales, el cual suele motivar la demanda); análisis de pruebas (p.ej. en la Sentencia T-658 de 2011 ya mencionada, la demandante buscó la empresa que hizo el reporte negativo para pedir la aclaración respectiva pero no la encontró porque la información de contacto era errónea. E1 juez de primera instancia no tuvo en cuenta esa gestión e indicó que no había hecho la gestión correspondiente, lo que confirmó el estado de indefensión de la demandante); consideración de la condición de víctima ( $\mathrm{T}-328 \mathrm{~A} / 12$, cuando no se tienen en cuenta estas excepciones válidas para justificar el incumplimiento de una obligación financiera).

Por último, el silencio administrativo genera asimetrías de información cuando las entidades no dan respuesta o solo responden en 
forma parcial (T-328A/12, T-419/13, T-036/16). Por ejemplo, en el caso de la Sentencia T-419 de 2013 el banco demandado no presentó extractos para soportar el sobregiro que justificó el reporte negativo del demandado y dio origen a la tutela. Y el caso de la Sentencia T-036 de 2016 donde la Procuraduría no dio una respuesta clara y oportuna al demandante.

En síntesis, esta tipología confirma que en las sentencias revisada la asimetría de información se presenta a diferentes niveles en un mismo proceso y que puede agravarse o no por la decisión del juez y las actuaciones de las partes involucradas. Aunque este resultado no se puede generalizar, el análisis de las sentencias indica que la obligación de información es la referencia en materia de normas para que el juez tome decisiones pero no elimina las asimetrías de información, debido a la complejidad y especificidad de cada caso y a los comportamientos oportunistas de los usuarios y de las entidades financieras que manipulan la información o según su conveniencia. Muchas veces, la información requerida se refiere a largos lapsos de tiempo entre el hecho y el momento en que se desata el conflicto. Este aspecto temporal es o puede ser utilizado por las partes en su propio beneficio, para ocultar, modificar o viciar la información.

\section{LA ACCIÓN DE TUTELA RELEGA LOS PROBLEMAS}

\section{DE ASIMETRÍA DE INFORMACIÓN A UN SEGUNDO PLANO}

El segundo resultado está estrechamente relacionado con la razón de ser de la acción de tutela y su funcionamiento. Si bien, en caso de un desacuerdo con una entidad financiera, el usuario debe recurrir a instancias judiciales como los juzgados civiles; cuando se viola un derecho constitucional, se puede solicitar la mediación de la Corte Constitucional a través de una acción de tutela.

La Corte resuelve las acciones de tutela siguiendo una serie de conceptos jurídicos humanamente no refutables, pero relega la asimetría de información a un segundo plano. Cuando el caso llega a la Corte Constitucional, su deber es examinar la posible violación de un derecho fundamental y no ahondar en la asimetría de información. Antes de pronunciarse, la Corte determina si la acción de tutela es procedente si se cumplen dos requisitos principales: la indefensión y la no disposición de otro medio de defensa judicial (CPC, art. 86), que como veremos son de gran interés en el análisis económico de la obligación de información.

Recordemos que toda persona tiene derecho a establecer una acción de tutela para reclamar ante los jueces, mediante un procedimiento 
preferente (no pueden transcurrir más de 10 días entre la solicitud y su resolución), la protección inmediata de sus derechos constitucionales, cuando sean vulnerados o amenazados por la acción de una autoridad pública o de particulares que presten un servicio público o cuya conducta afecte grave y directamente el interés colectivo, o cuando el solicitante se halle en estado de subordinación o indefensión ${ }^{5}$. Además, la acción de tutela responde al principio de subsidiariedad, es decir, no es un mecanismo de defensa judicial alternativo o supletorio de los recursos ordinarios previstos para amparar un derecho ${ }^{6}$.

Aunque la Corte especifica que las controversias de carácter contractual se deben resolver mediante acciones ordinarias de carácter civil, comercial o contencioso según el $\mathrm{caso}^{7}$, la jurisprudencia indica que la acción de tutela es procedente cuando las demás acciones judiciales no son eficaces para proteger el derecho fundamental o evitar que haya un perjuicio irremediable ${ }^{8}$. La Corte indica que para excluir automáticamente la procedencia de la tutela no es suficiente la existencia de otro procedimiento judicial; es indispensable que sea idóneo y eficaz: "con miras a lograr la finalidad específica de brindar inmediata y plena protección a los derechos fundamentales, de modo que su utilización asegure los efectos que se lograrían con la acción de tutela" (Sentencia T-468/99). En suma, los dos requisitos para decidir la procedencia -indefensión y subsidiariedad-están sujetos a la idoneidad de los mecanismos de defensa a disposición del demandante y a la constatación de un perjuicio irremediable.

El examen de las 25 sentencias de la Corte Constitucional muestra que las decisiones se basan en la valoración de los derechos constitucionales individuales. La discreción del juez reposa en conceptos lejanos a las fallas de mercado mencionadas en la primera parte. Se tiende a dar preeminencia al respeto de la dignidad y de la vida íntima de las personas y no al origen de las asimetrías de información. Así, el conflicto causado por estas se resuelve considerando la vulneración de derechos fundamentales.

${ }^{5}$ Ver, p. ej., las sentencias T-328 de 2012, T-136 de 2013.

${ }^{6}$ Ver, entre otras, las sentencias T-1093 y T-1140 de 2004, T-742 de 2011 y T-086 de 2012.

7 Ver, p. ej., la sentencia T-086 de 2012.

${ }^{8}$ La sentencia T-225 de 1993 define un perjuicio irremediable como: i) inminente para que justifique las medidas prudentes y oportunas; ii) grave e irreparable, lo que equivale a la intensidad del daño material o moral de la persona; iii) las medidas han de ser urgentes (prontitud del perjuicio). La urgencia y la gravedad determinan que la acción de tutela sea impostergable, ya que puede ser ineficaz si es inoportuna. 
Esto puede ser explicado por la naturaleza del Habeas Data, un derecho legal consagrado por la ley y un derecho fundamental consagrado por la Constitución. Como derecho fundamental, está relacionado con otros derechos constitucionales como el derecho a la vivienda digna, el derecho a la intimidad, el derecho a la autodeterminación informática y otros que veremos a continuación. Si no se cumplen las disposiciones de la Ley 1266 de 2008 sobre el uso de la información personal, el titular de la información puede entablar una tutela para exigir la protección de sus derechos fundamentales. Así, los conflictos ocasionados por asimetrías de información llevan a considerar la vulneración del derecho al Habeas Data, lo cual lleva potencialmente a considerar la vulneración de otros derechos fundamentales, a través de lo que se podría llamar una cadena de derechos. Las sentencias que presentamos a continuación ilustran cómo se aplican la Ley de Habeas Data y otros derechos fundamentales en situaciones de asimetría de información.

La Sentencia T-198 de 2015 ilustra la prevalencia del derecho fundamental de acceso a la información y del deber de conservar documentos a cargo de las entidades que custodian y administran información contenida en archivos y bases de datos. En este caso, la demandante presentó acción de tutela contra un hospital, por considerar que había vulnerado su derecho fundamental al acceso a la información, al negarse a expedir el certificado del tiempo de servicios que había prestado allí en 1969, 1970 y 1971, el cual requería para tramitar su pensión. Como la demandante era sujeto de protección especial y carecía de recursos para su manutención, el hecho de que el hospital no le entregara el certificado laboral que le habría reportado unos ingresos que le permitieran tener una vida digna ponía en entredicho la buena fe del hospital. Al vulnerar el derecho al acceso a la información pública, se vulnera el derecho a ejercer control sobre las acciones personales y el derecho a la libertad. En este caso el fallo del juez se basó en el derecho al habeas data, al debido proceso y al acceso a documentos públicos.

La Sentencia T-811 de 2010 ilustra el caso de una empresa de transporte urbano que entabló acción de tutela contra dos entidades financieras argumentando que habían vulnerado su derecho fundamental al habeas data al reportar calificaciones de crédito negativas ajustadas a las calificaciones de otras entidades del sector y no correspondientes a la realidad. Aquí, el problema de información es la veracidad de la calificación de riesgo de la empresa de transportes. Para las dos entidades financieras, el nivel de riesgo correspondía al 
que reportaron otras entidades, que lo habían calificado como crédito tipo D. Según el transportador, su calificación pasó de $\mathrm{D}$ a A, y esas dos entidades debían de haber tomado en cuenta esa nueva información antes de hacer su reporte a las centrales de riesgo. Este es un problema de riesgo moral. Reiterando que uno de los principios de la administración de datos es la veracidad, el fallo se basó en la vulneración del derecho al habeas data, la cual llevó a vulnerar el derecho de autodeterminación informática y el derecho a la libertad. Según la sentencia, este último derecho es vulnerado "cuando la información que circula sobre una persona, natural o jurídica, no es veraz". La Corte no resuelve el conflicto rectificando la información sobre calificación del riesgo de crédito de la empresa de transportes pues no verifica su capacidad de crédito ni pide información al respecto. Decide apoyándose en la vulneración en cadena de derechos fundamentales y no en el origen del conflicto: la asimetría de información.

La Sentencia T-017 de 2011 instruye un caso en el que la veracidad de los datos suministrados a la central de riesgos no fue respaldada por documentos probatorios. El reporte respectivo afecta el derecho a la vida íntima de la demandante y vulnera su derecho al habeas data y al buen nombre. La demandante instauró una tutela contra una entidad financiera y una central de riesgos basada en la presunta violación de sus derechos fundamentales al mantener el reporte negativo por una obligación que según ella había cancelado. En el año 2000 recibió una certificación de la compañía financiadora en la que constaba que su tarjeta de crédito estaba a paz y salvo. La compañía argumentó que "el paz y salvo fue generado debido a un problema operativo al interior del sistema, toda vez que la tarjeta presentaba un saldo pendiente", y requería que la demandante pagara la obligación pendiente. Pero no entregó documentos que probaran la existencia del saldo pendiente. La Corte concluyó que la compañía vulneró los derechos al habeas data financiero y al buen nombre de la demandante, pues incumplió los requisitos de veracidad y de certeza al reportar datos negativos sin documentos de respaldo. Si la fuente de información no presenta soportes de la obligación en mora queda en entredicho la veracidad de los datos suministrados y en duda su buena fe.

La lectura de esta sentencia revela problemas de información, de riesgo moral y de oportunismo que el juez no estudió a la hora de considerar la vulneración de los derechos fundamentales. No hay certeza de la existencia de la obligación porque no hay pruebas y se afirma que el paz y salvo fue emitido por error. Hay contradicciones entre la información suministrada por la entidad financiera y por la 
central de riesgos (según esta, la obligación pasó a cartera castigada en enero de 2010, por estar en mora desde febrero de 2006, mientras que según la entidad financiera la tarjeta de crédito fue bloqueada por falta de pago en 1997). Se confía en la buena fe de la demandante, que sabe si canceló o no la obligación. La Corte no ahonda en el problema de información y no considera un posible comportamiento oportunista de la demandante pues esta última nunca precisó cuando hizo el pago que dio lugar al paz y salvo. Así, confía en la buena fe de la demandante y asume el error del sistema. Es cierto que la obligación de información exige que las entidades financieras conserven registros de sus operaciones. Su pérdida es una falta grave que debe ser sancionada. Pero se habría podido considerar el riesgo moral origen de este conflicto, en vez de desplazarlo a un segundo plano.

Las hipótesis y los mecanismos económicos descritos en la primera parte ayudan a entender las decisiones de la Corte. Debido a la complejidad de las situaciones, a su carácter único y a los costos que generan las sentencias solo resuelven parcialmente las asimetrías de información. En la Sentencia T-811 de 2010 antes descrita, la solución de un conflicto que consiste en determinar la veracidad de la calificación del riesgo de crédito implicaría a la Corte hiciera una auditoría a esta empresa. ¿Quién asumiría ese costo, las entidades financieras que reportaron la información a las centrales de riesgo, la empresa de transportes o la Corte?

El análisis de las sentencias identifica enormes costos de transacción que tendrían que cubrir los usuarios, las entidades financieras, la Corte y demás instituciones involucradas. Por ejemplo, los costos administrativos asociados a la verificación y validación de los datos enviados a las centrales de riesgo y a las solicitudes de información y corrección de antecedentes, los costos de abogados, tribunales y recursos a otras instancias judiciales, el tiempo dedicado a revisar la jurisprudencia y la legislación vigente, la coordinación entre entidades, los costos de los procesos de cobro (llamadas, correos, visitas a deudores, fiadores), los costos de búsqueda de información y de determinación de la veracidad de los documentos y testimonios, etc.

En suma, los conflictos entre usuarios y entidades financieras ocurren a causa del comportamiento de los agentes y de las características del mercado. En las sentencias analizadas, la complejidad de la asimetría de información lleva a resolver el problema únicamente con instrumentos jurídicos. E1 juez utiliza la faceta del derecho legal del habeas data y de la obligación de información cuando la asimetría 
de información es "fácil" de identificar y de resolver, cuando es más difícil emplea los derechos fundamentales para proteger al consumidor financiero. Desde la perspectiva jurídica, el recurso a los derechos fundamentales para resolver una tutela tiene sentido. Pero desde la perspectiva económica, sobreponerlos a la asimetría de información no ataca el origen de las asimetrías, y así se corre el riesgo de que reaparezcan en otras transacciones.

\section{CONCLUSIÓN}

No sería justo desconocer que las normas sobre la obligación de información disciplinan a los usuarios y a las entidades financieras, exigiendo la preservación de la información, determinando las responsabilidades de las entidades bancarias, el carácter suficiente e idóneo de la información y sus pautas de divulgación y suministro, entre otras medidas ya mencionadas. Sin embargo, de acuerdo con las sentencias estudiadas, la aplicación de dicha obligación se ve limitada por la complejidad de la información, la ignorancia financiera de los usuarios y las ventajas de información que suelen beneficiar a las entidades financieras.

E1 análisis detallado de las 25 sentencias permitió construir una tipología (cuadro 1) en la que los problemas de información surgen durante la transacción entre usuarios y entidades financieras y durante el proceso de las sentencias. En el primer caso, debido a la prescripción de la deuda, la transgresión de derechos que afectan derechos económicos, la violación de derechos fundamentales, la información inexistente o datos errados y el hecho superado. En el segundo caso, debido a la complejidad de los casos, la coordinación entre las entidades demandadas, la coordinación entre juzgados o la falta de claridad en los procesos y en el alcance de las decisiones, así como al silencio administrativo.

De esta tipología se obtuvo un primer resultado: en las sentencias revisadas, la obligación de información no elimina la asimetría de información en el sector bancario. Según el análisis de las sentencias, la respuesta a la pregunta de hasta qué punto resuelven los problemas de información depende de la decisión que toma la Corte. En algunos casos es concluyente pues ordena el retiro de reportes negativos que afectan los derechos de los demandantes. En otros casos, solo establece responsabilidades y plazos para revisar la información de la transacción que dio origen al conflicto, debido a las razones que se mencionan en el artículo. 
El análisis empírico llevó a un segundo resultado sobre el alcance de la obligación de información: debido a la complejidad de este problema las autoridades judiciales se pronuncian recurriendo a criterios legales como los derechos fundamentales, y relegan los problemas de información a un segundo plano. Así, los conflictos pasan de ser problemas contractuales a casos de violación de un derecho fundamental que dan lugar a acciones de tutela. Aunque el origen de los conflictos sea un problema de información, la Corte los resuelve evitando la posible violación de derechos fundamentales, sin resolver las asimetrías de información.

Por último, la buena fe parece ser el denominador común en las sentencias revisadas. Los testimonios y actuaciones de los demandantes y de los demandados son la base para esclarecer los conflictos y llegar a una decisión. Aunque según la teoría económica los agentes se pueden comportar en forma oportunista para lograr sus intereses personales. Jurídicamente, el principio de buena fe está asociado a los derechos fundamentales y al debido proceso. La sentencia T-672 de 2010 explica que las actuaciones de las instituciones públicas o privadas que actúan en el marco jurídico colombiano están regidas constitucionalmente por los postulados de la buena fe y la confianza legítima. La sentencia T-328A de 2012 va más allá y recuerda que

si estas mínimas exigencias de humanidad y consideración no estuvieran fundadas en derechos y principios como los de dignidad del ser humano, solidaridad, lealtad y buena fe y no fueran jurídicamente exigibles en supuestos de afectación de derechos fundamentales, habría que concluir que la democracia constitucional colombiana ha sido suplantada por un rígido formalismo jurídico.

Así, se contraponen dos bases de análisis en los conflictos contractuales. En economía prima la sospecha del oportunismo y en derecho, la buena fe. La resolución de los conflictos exige flexibilidad y el análisis caso por caso. E1 desafío para todas las partes involucradas es minimizar los costos de transacción generados por la asimetría de información que origina el conflicto.

\section{REFERENCIAS BIBLIOGRÁFICAS}

Ahlin, C. y Waters, B. (2016). Dynamic microlending under adverse selection: Can it rival group lending? Journal of Development Economics, 121, 237-257.

Akerlof, G. A. (1970). The market for "lemons": Quality uncertainty and the market mechanism. Quarterly Journal of Economics, 84(3), 488-500. 
Alonso L. y Monge P. (2017). Evolución legal en los deberes de conducta y de información en materia de contratación de productos de inversión. Actualidad civil, 4, 51-61.

Becker, G. S. (1968). Crime and punishment: An economic approach. Journal of Political Economy, 76(2), 169-217.

Blanco, B. C. (2012). La información como instrumento de protección de los consumidores, los consumidores financieros y los inversionistas consumidores. Opinión Jurídica, 11(21), 135-152.

Boerner C. y Macher J. (2001). Transaction cost economics: An assessment of empirical research in the social sciences. Business and Politics, 10(1), 10-63.

Calabresi, G. (1970). The Costs of Accidents: A Legal and Economic Analysis. New Haven: Yale University Press.

Coase, R. H. (1960). The problem of social cost. Journal of Law and Economics, 3, 1-44.

Congreso de la República de Colombia. (2008). Ley 1266 de 2008, Diario Oficial n. 47.219.

Congreso de la República de Colombia. (2009). Ley 1328 de 2009, Diario Oficial n. 47.411.

Constitución Política de Colombia. (1991). 2. ${ }^{a}$ ed. Bogotá: Legis.

Cooter, R. y Ulen, T. (2016). Law and economics. Boston: Addison-Wesley.

Cuena, C. M. (2017). Intercambio de información positiva de solvencia y funcionamiento del mercado de crédito. InDret, 3, 1-66.

Daughety, A. y Reinganum J. (2005). Economic theories of settlement bargaining. Review of Law and Social Sciences, 35, 35-59.

Díaz, A. (2013). Retos normativos y de supervisión para el 2013. Revista Fasecolda, 151, 46-50.

Jiménez, M. F. (2014). Efectos del sistema de atención al consumidor financiero (SAC) en el tratamiento de la exigencia legal de educación al consumidor financiero. Revista Civilizar de empresa y economía, 5(9), 69-86

Kreps, D. y Wilson R. (1982). Reputation and imperfect information. Journal of economic theory, 2, 253-279

Macneil, I. R. (1980). Power, contract, and the economic model. Journal of Economic Issues, 14(4), 909-923.

Medema S. G. (1997). Coasean economics: Law and economics and the institutional economics. Nueva York: Springer.

Moisander, J. Hirsto, H. et al. (2016). Emotions in institutional work: A discursive perspective. Organization Studies, 37(7), 963-990.

Monsalve, C. V. y Rodado, B. D. (2010). La importancia de la obligación de información en las relaciones financieras de consumo: Una aproximación económica y jurídica. Revista de derecho, 33, 158-182.

Muñoz, S. C. (2012). El deber de información al consumidor financiero: caso de los deudores de créditos hipotecarios en la crisis del 2008. Revista. e-mercatoria, 11(2), 146-178.

Pinzón, C. M. (2010). Aproximaciones del análisis económico del derecho. Bogotá: Universidad Externado de Colombia.

Pinzón, C. M. (2013). La nueva economía institucional: un puente para el estudio del derecho y desarrollo. En C. A. Naranjo, C. Blanco et 
al. (eds.), El derecho del consumo (pp. 169-225). Bogotá: Universidad Externado de Colombia.

Prasad, P. (2017). Crafting qualitative research: Beyond positivist traditions. Nueva York: Routledge.

Speklé, R. (2003). Case study research in the new institutional economics. Documento de trabajo presentado en la European School of New Institutional Economics, Cargèse, Francia.

Stigler, G. J. (1961). The economics of information. Journal of Political Economy, 69(3), 213-225.

Stiglitz, J. E. (1992). On the economic role of the State. Oxford: Basil Blackwell.

Vázquez, C. (2012). Protección al consumidor financiero: avances y retos del sector asegurador. Bogotá: Fasecolda.

Williamson, O. (1979). Transaction-cost economics: The governance of contractual relations. Journal of Law and Economics, 22(2), 233-261. 